\title{
Comparative study between pi and fuzzy pi controllers for DFIG integrated in variable speed wind turbine
}

\author{
H. Mesai Ahmed ${ }^{1}$, A. Bentaallah ${ }^{1}$, Y. Djeriri ${ }^{1}$, A. Mahmoudi ${ }^{2,3}$ \\ ${ }^{1}$ ICEPS Intelligent control and electrical power systems Laboratory, University of Sidi Bel Abbes, ALGERIA \\ ${ }^{2}$ LMSE Laboratoire Modélisation des Systeme Energitique, University of Biskra, ALGERIA \\ ${ }^{3}$ CISE - Electromechatronic Systems Research Centre, University of Beira Interior, Covilhã, PORTUGAL \\ Hamzamesai2@hotmail.com
}

\begin{abstract}
This paper presents the contribution of the application of fuzzy logic for the independent control of the active and reactive power stator of a doubly fed induction generator (DFIG), used in a variable speed wind energy conversion system. So in this work, we are particularly interested in the application of indirect vector control by stator flux orientation to the DFIG, based on fuzzy controllers. These latter surpass the limits of conventional controllers and possess essential characteristics for the improvement of the robustness of the vector control with against parameters variations of the system. The obtained simulation results have shown that it is possible to control the stator powers, even in the presence of parametric variations.
\end{abstract}

Keywords: Wind Energy - Doubly Fed Induction Generator - Vector Control - Fuzzy Logic

Received: 12/11/2019 - Accepted: 15/12/2019

\section{Introduction}

The new wind turbines technology work at variable spee ds.this type of operation allows energy efficiency to be in creased, mechanical loads to be reduced and the perform ance of the electrical energy generated to be improved.

Compared to the wind turbines at fixed speed, Such wind turbines often use the Doubly Fed generator of induction (DFIG) $[1,2]$. The Indirect vector control based on conventional regulators PI type (ProportionalIntegral) is traditionally used to control the active and reactive power of DFIG $[3,4]$. This technique decouples the rotor current active and reactive components are obtained indirectly by controlling the input currents.

Artificial intelligence techniques are currently known for their great potential to solve problems related to industrial processes. These techniques include genetic algorithms, neural networks and fuzzy logic that are increasingly applied in the control of the induction machine and the adaptation of its vector control [5]. In our study, we looked at fuzzy logic to synthesize robust regulators against DFIG parametric variations to replace the four conventional IP controllers used in vector control. Simulation results are presented to show the effectiveness of these regulators in solving the robustness problem so that they compare their performance with conventional regulators.

\section{Simplified model of DFIG}

The DFIG is represented by Park model (d-q) whose equations are established in a reference related to the rotating field as follows [6]:

- The Terminal voltages

$$
\left\{\begin{array}{l}
V_{s d}=R_{s} i_{s d}+\frac{d}{d t} \phi_{s d}-\omega_{s} \phi_{s q} \\
V_{s q}=R_{s} i_{s q}+\frac{d}{d t} \phi_{s q}+\omega_{s} \phi_{s d}
\end{array}\right.
$$

- The rotor voltages

$$
\left\{\begin{array}{l}
V_{r d}=R_{r} i_{r d}+\frac{d}{d t} \phi_{r d}-\left(\omega_{s}-\omega_{r}\right) \phi_{r q} \\
V_{r q}=R_{r} i_{r q}+\frac{d}{d t} \phi_{r q}+\left(\omega_{s}-\omega_{r}\right) \phi_{r d}
\end{array}\right.
$$




$$
\left\{\begin{array}{c}
\left.\Psi_{s}=L_{s} i_{s d}+L_{m}^{(}\right) i_{r d} \\
0=L_{s} i_{s q}+L_{m}^{(2)} i_{r q}
\end{array}\right.
$$

The active and reactive statoric powers are expressed by:

$$
\left\{\begin{array}{l}
P_{s}=\frac{3}{2}\left(v_{s d} i_{s d}+v_{s q} i_{s q}\right) \\
Q_{s}=\frac{3}{2}\left(v_{s q} i_{s d}-v_{s d} i_{s q}\right)
\end{array}\right.
$$

From equation (7), we can write:

- The electromagnetic torque

$$
C_{e m}=\frac{3}{2} p \frac{L_{m}}{L_{s}}\left(\Phi_{s q} i_{r d}-\Phi_{s d} i_{r q}\right)
$$

With: $p$ is the number of pole pairs of the DFIG.

In view of DFIG's vector control; it makes more sense to choose the d-q coordinator related to the statoric rotating field, which is related to the frequency of $50 \mathrm{~Hz}$ (frequency of the electrical grid). Therefore, Park's coordinator will be synchronized with the statoric flux (Figure 1)

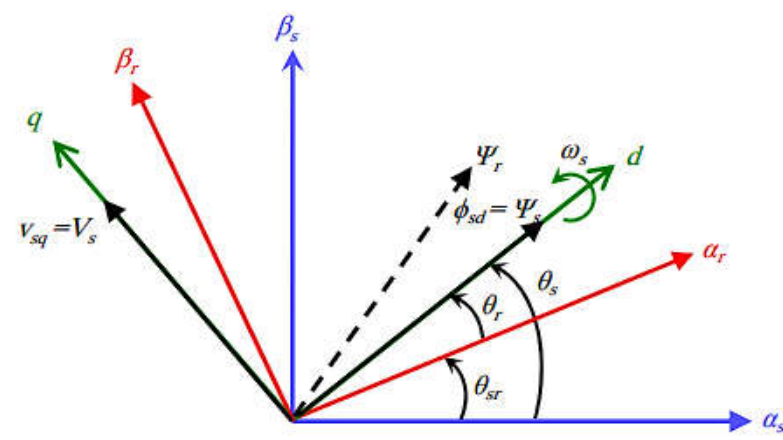

Figure 1. Stator flux orientation

Often in the case of a DFIG medium and high power, the stator resistance Rs is neglected during the synthesis of the model according the assumption of orientation of the stator flux $[7,8]$.

By adopting the hypothesisof negligible stator resistance $R s$ and the stator flux is constant and oriented according to the d-axis, we deduce:

$$
\begin{aligned}
& \left\{\begin{array}{l}
\phi_{s q}=0 \\
\phi_{s d}=\Psi_{s}
\end{array}\right. \\
& \left\{\begin{array}{l}
V_{s d}=0 \\
V_{s q}=V_{s}=\omega_{s} \Psi_{s}
\end{array}\right.
\end{aligned}
$$

with : $\sigma=1-\left(L_{m}^{2} / L_{s} L_{r}\right) \quad$ (4) ispersion coefficient of Blondel).

By substituting the expression (9) of the rotor flux in equation (2) we obtain

$$
\left\{\begin{array}{l}
V_{r d}=R_{r} i_{r d}+\sigma L_{r} \frac{d}{d t} i_{r d}-g \omega_{s} \sigma L_{r} i_{r q} \\
V_{r q}=R_{r} i_{r q}+\sigma L_{r} \frac{d}{d t} i_{r q}+g \omega_{s} \sigma L_{r} i_{r d}+g \frac{L_{m} V_{s}}{L_{s}}
\end{array}\right.
$$

In steady state, the terms involving derivatives of the diphasic rotor currents disappear, we can write:

$$
\left\{\begin{array}{l}
V_{r d}=R_{r} i_{r d}-g \omega_{s} \sigma L_{r} i_{r q} \\
V_{r q}=R_{r} i_{r q}+g \omega_{s} \sigma L_{r} i_{r d}+g \frac{L_{m} V_{s}}{L_{s}}
\end{array}\right.
$$

The adaptation equations powers (3) with the axis system chosen and the simplifying assumptions made in this case $\left(V_{s d}=0\right)$ gives:

$$
\left\{\begin{array}{l}
P_{s}=\frac{3}{2} V_{s} i_{s q} \\
Q_{s}=\frac{3}{2} V_{s} i_{s d}
\end{array}\right.
$$

By replacing the stator currents by their values the equation (8) in equation (12) we obtain the following expressions for the active and reactive power:

$$
\left\{\begin{array}{l}
P_{s}=-\frac{3}{2} V_{s} \frac{L_{m}}{L_{s}} i_{r q} \\
Q_{s}=\frac{3}{2}\left(V_{s} \frac{\Psi_{s}}{L_{s}}-V_{s} \frac{L_{m}}{L_{s}} i_{r d}\right)
\end{array}\right.
$$


By pulling $\Psi_{s}=\frac{V_{s}}{\omega_{s}}$ the equation (6), the expression of reactive power becomes:

$Q_{s}=-\frac{3}{2} V_{s} \frac{L_{m}}{L_{s}} i_{r d}+\left(\frac{3 V_{s}^{2}}{2 L_{s} \omega_{s}}\right)$

Given the chosen coordinator, approximations made and if we consider the magnetizing inductance $\mathrm{Lm}$ as constant (constant air gap), the resulting system proportionately links the active power to the rotor q-axis current and the reactive power to the rotor d-axis at a constant $\left(3 V_{s}^{2} / 2 L_{s} \omega_{s}\right)$ imposed by the grid.

Replacing (6) in (4), the DFIG torque will be expressed:

$$
C_{e m}=-\frac{3}{2} p \frac{L_{m}}{L_{s}} \Psi_{s} i_{r q}=-\frac{3}{2} p \frac{L_{m} V_{S}}{L_{s} \omega_{s}} i_{r q}
$$

\section{Indirect Vector control of DFIG}

This method involves taking into account the terms of coupling $(\mathrm{Cd}$ and $\mathrm{Cq})$ and compensating them by using a system with two loops to control rotor power and currents, based on conventional IP-type regulators

(Proportional-Integral).

The block diagram of the system is thus reproduced in the opposite direction, resulting in a model corresponds to that of the machine but in the other direction which contains all the elements of the block diagram of the DFIG.

In this method, decoupling is done at the outputs of the current regulators rotor with a feedback, which allows the adjustment of the powers (Figure 2). In our work, the design of these regulators is achieved by the method of compensation of the dominant poles.

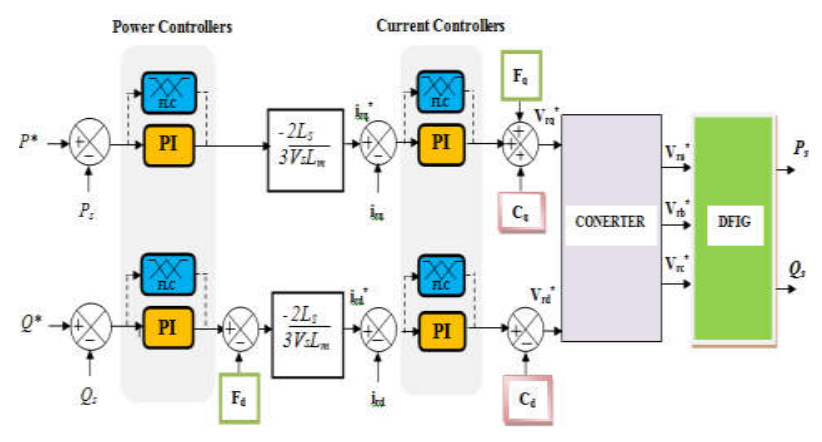

Figure 2. Block diagram of the indirect control with power loops
With: $\left\{\begin{array}{l}C_{d}=g \omega_{s} \sigma L_{r} i_{r q} \\ C_{q}=g \omega_{s} \sigma L_{r} i_{r d}\end{array}\left\{\begin{array}{l}F_{d}=\frac{3 V_{s}^{2}}{2 L_{s} \omega_{s}} \\ F_{q}=\frac{g L_{m} V_{s}}{L_{s}}\end{array}\right.\right.$

\section{Fuzzy Logic Control}

The advantage of fuzzy control over conventional controls is that it does not require knowledge of mathematical models of the system. On the other hand, it needs a set of rules based mainly on the knowledge of a qualified operator manipulating the system [9].

The design of the fuzzy controller (FLC) through four main distinct steps is shown in Figure 3. The two most significant variables to analyze the behavior of the system to know the error and its variation are chosen as the two inputs of the controller by fuzzy logic (RFL).

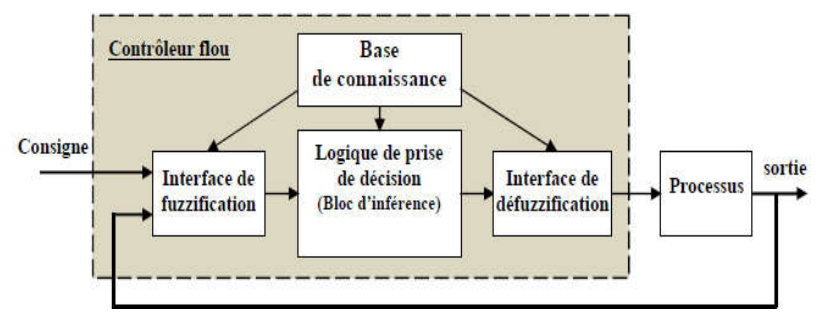

Figure 3. Basic structure of a fuzzy logic control [11,12]

The output is the increment of the control signal applied to the system to be controlled $d I_{q r}$ (see Figure 4).

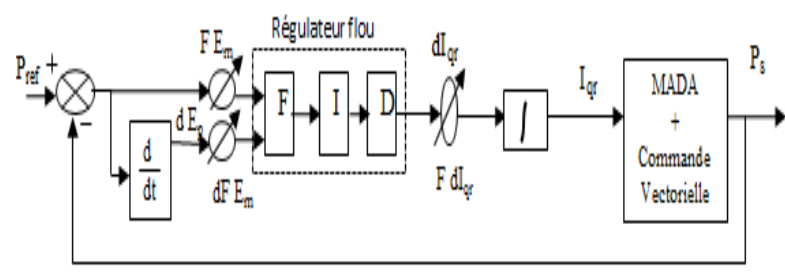

Figure 4. The DFIM control system Block diagram

The RFL inputs are calculated at time $\mathrm{K}$ as follows [12, $13]$.

$$
\begin{aligned}
& E_{p}(k)=P_{r e f}(k)-P_{s}(k) \\
& d E_{p}(k)=E_{p}(k)-E_{p}(k-1)
\end{aligned}
$$

Thee $I_{r q}^{r e f}$ control signal is obtained after the integration of the RFL output

$$
I_{r q}^{r e f}(k)=I_{r q}^{r e f}(k-1)+d I_{r q}^{r e f}(k)
$$


The same reasoning and procedure applies to the reactive power loop where the control signal is the direct rotoric current $I_{r d}^{r e f}$.

The fuzzy regulator shown in figure 4 is composed of [11]:

- The triangular and trapezoidal membership functions, this choice is due to the simplicity of implementation

- A standardized universe of discourse; The universe of discourse is divided into three (fine adjustment) for the input and output variables

- Mamdani's involvement in inference.

- The Centre of Gravity Method for defuzzification.

\section{a. Fuzzification}

For the membership functions, triangular and trapezoidal shapes were chosen for each variable as shown in Figure 5[9]:

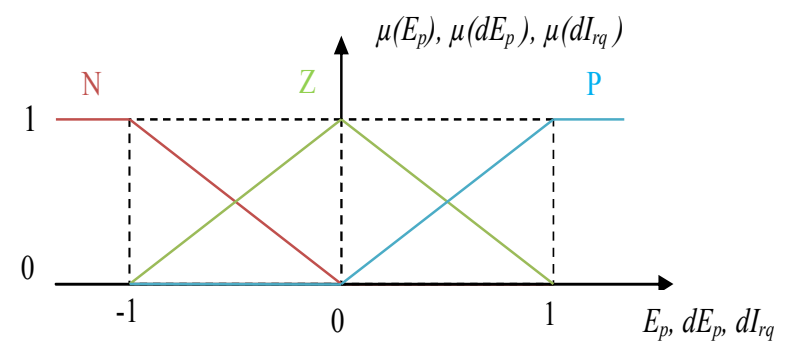

Figure 5. Membership functions for input variables $E_{P}, d E_{P}$ and outlet $d I_{r q}$ of the fuzzy controller of active power.

\section{b. Inference}

As mentioned before, each of the two linguistic inputs of the fuzzy controller has three fuzzy sets, resulting in a set of nine rules. These can be represented by the following inference matrix [7]

\begin{tabular}{|c|c|c|c|c|}
\hline \multirow{2}{*}{\multicolumn{2}{|c|}{$d I_{r p}$}} & \multicolumn{3}{|c|}{$d E_{p}$} \\
\hline & & $\mathrm{N}$ & $\mathrm{Z}$ & $\mathrm{P}$ \\
\hline \multirow{3}{*}{$E_{P}$} & $\mathrm{~N}$ & $\mathrm{~N}$ & $\mathrm{~N}$ & $Z$ \\
\hline & Z & $\mathrm{N}$ & Z & $\mathrm{P}$ \\
\hline & $P$ & $\mathrm{Z}$ & $P$ & $P$ \\
\hline
\end{tabular}

Table 1. Inference matrix of the fuzzy power regulator.

\section{c. Defuzzification}

For defuzzification, we use the method of the center of gravity presented previously, we obtain

$$
d I_{r q}=\frac{\sum \mu_{R i}\left(I_{r q i}\right) d I_{r q i}}{\sum \mu_{R i}\left(I_{r q i}\right)}
$$

DFIG's indirect power control strategy through fuzzy logic was validated by numerical simulation using MATLAB/SIMULINK software:
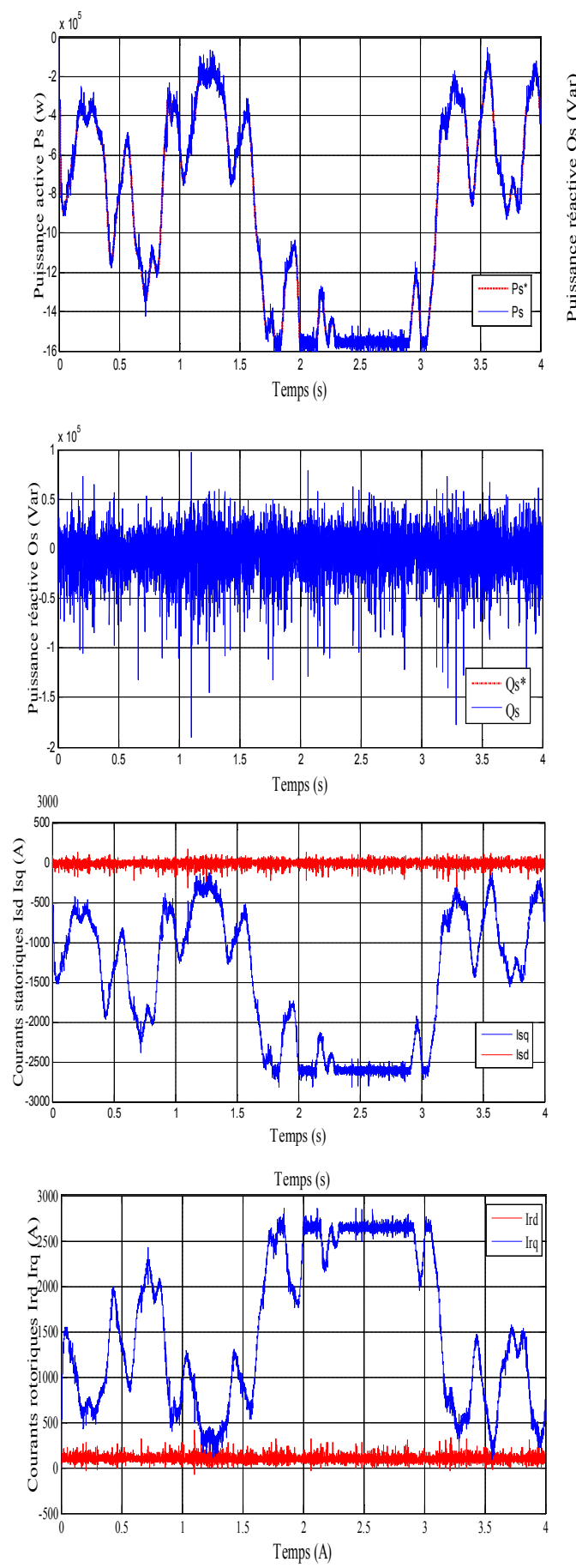

Figure 6. Simulation results of the DFIG vector control based on fuzzy controllers (RFL), at variable wind speed

The simulation results presented in Figure 6 show that the fuzzy controller offers better dynamic and static performance of power reference tracking, with a very fast response time, no overshoot and an almost zero static error. 


\subsection{Robustness test}

The purpose of this test is to test the robustness of the technique of two controllers (PI -RLF) against variations in DFIG parameters. We will perform a decrease in the mutual inductance $(30 \%$ of $\mathrm{Lm})$, which corresponds to a saturation effect of the machine's magnetic circuit.

From the results obtained in Figure 7, it can be seen that the fuzzy controller retains its robustness in the face of the variation in mutual inductance, while the PI controller loses its robustness completely.
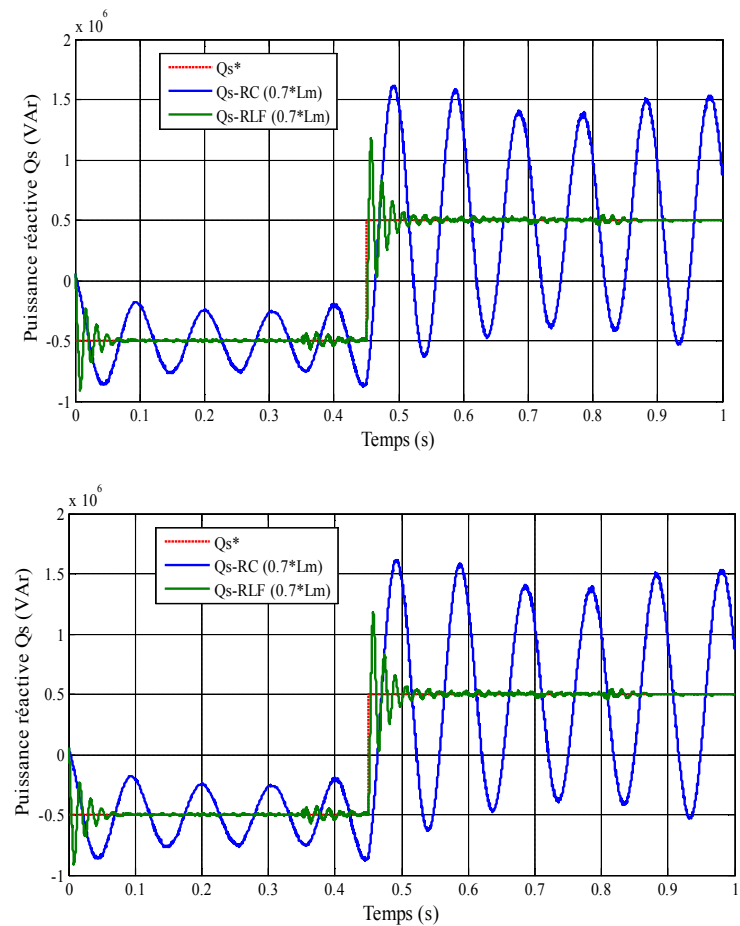

Figure 7. Robustness test of controllers against DFIG parametric variations

We can summarize the dynamic and static performance obtained by the two regulators in normal operation (without parametric change) by the following table:

Table 2. Performance Comparison of the two regulators

\begin{tabular}{|c|c|c|c|}
\hline & & \multicolumn{2}{|c|}{ Controller } \\
\hline \multicolumn{2}{|c|}{ Performances } & PI & RLF \\
\hline \multicolumn{2}{|c|}{ Response time (ms) } & 6 & 1.95 \\
\hline \multicolumn{2}{|c|}{ Exceedance (\%) } & 6 & 6 \\
\hline \multirow{2}{*}{ Static error } & $(\%)$ & 0.6 & 1.42 \\
\hline & (W) & 9000 & 21000 \\
\hline \multicolumn{2}{|c|}{$\begin{array}{l}\text { Robustness to variation } \\
\text { parameters }\end{array}$} & Bad & acceptable \\
\hline \multicolumn{2}{|c|}{ Conception } & Simple & difficult \\
\hline
\end{tabular}

\section{Conclusion}

In this paper, the robust vector control of DFIG based on fuzzy logic technique has been presented, whose notion of the offline decision table is implemented in the vector control of DFIG. This choice of command was justified by the ability of fuzzy logic to deal with imprecision, uncertainty and vagueness.

From the simulation results obtained, it can be said that the fuzzy controller provides significant robustness to the vector control of the DFIG, with respect to the parametric variations of the latter, in particular the mutual inductance.

By comparison, fuzzy controllers offer significant improvements over conventional controllers in terms of speed of transient regimes and insensitivity to parametric variations in the system.

\section{References}

[1] T. Ghennam, "Supervision d'une ferme éolienne pour son intégration dans la gestion d'un réseau électrique, Apports des convertisseurs multi niveaux au réglage des éoliennes à base de machine asynchrone à double alimentation", Thèse de Doctorat de l'Ecole Militaire Polytechnique d'Alger, Algérie, Septembre 2011.

[2] L. Peng, "Reconfiguration du dispositif de commande d'une éolienne en cas de creux de tension", Thèse de Doctorat, Ecole centrale de Lille, France, juin 2010.

[3] B. Hopfensperger, D.J. Atkinson, R. Lakin. 'Stator-Flux-Oriented Control of a Doubly-Fed Induction Machine with and without Position Encoder', IEEE Proceedings - Electric Power Applications, Vol. 147, $\mathrm{N}^{\circ} 4,2000$, pp. 241 - 250.

[4] M. Yamamoto, O. Motoyoshi. "Active and Reactive Power Control for Doubly-Fed Wound Rotor Induction Generator", IEEE Transactions on Power Electronics, Vol. 6, N4, 1991, pp. 624 - 629.

[5] H. Mesai Ahmed, Y. Djeriri, A.Bentallah, "Robust Power controlof DFIG using artificial neural networks for a wind energy conversion system based energy storage unit". 2nd International Symposium Mechatronics, Renewable Energy ISMRE'2018 El-Oued, Algeria. 2018.

[6] Yaichi, I., Semmah, A., Wira, P. and Djeriri, Y. "Supertwisting Sliding Mode Control of a Doubly-fed Induction Generator Based on the SVM Strategy". Periodica Polytechnica Electrical Engineering and Computer Science, Vol. 63, N³, 2019, pp.178-190.

[7] Y. Djeriri, A. Meroufel. "Commande Vectorielle par les Réseaux de Neurones Artificiels d'une MADA Intégrée à un Système Eolien"; 6th International Conference on Electrical Engineering, 2010, pp. 33-37. Algeria.

[8] S. Muller, M. Deicke and R.W. De Doncker. "Doubly Fed Induction Generator Systems for wind turbines"', IEEE Industry Applications Magazine, 2002, pp. 26 - 33.

[9] E.H. Mamdani and S. Assilian. "An Experiment in Linguistic Synthesis with a Fuzzy Logic Controller", International Journal of Machine Studies, 1975, Vol. 7, pp. 1 - 13.

[10] M.J. Hany. "Design and Implementation of NeuronFuzzy Vector control for Wind-Driven Doubly-Fed 
Induction generator", IEEE Transactions on Sustainable Energy Conversion, Vol. 2, N4, 2011.

[11] A. Chaiba, R. Abdessemed, M.L. Bendaas A. Dendouga. "Performances of Torque Tracking Control for Doubly Fed Asynchronous Motor using PI and Fuzzy Logic Controllers"', Journal of Electrical Engineering, Vol. 5, N², 2005 , pp. $25-30$.

[12] Z. Boudjema, A. Meroufel Y.Djeriri. "Nonlinear Control of a Doubly Fed Induction Generator for Wind Energy Conversion", Carpathian Journal of Electronic and Computer Engineering, Vol. 6, $\mathrm{N}^{\circ} 1,2013$ pp. 28 - 35.

[13] K. Mouilah, M. Abid, A. Naceri M. Allam. "Fuzzy Control of a Doubly Fed Induction Generator for Wind Turbines", Journal of Electrical Engineering, JEE, Vol. 14, Nº 4, 2014, pp. 352 - 357. 